\title{
Comparative performance assessment of the most commonly used personnel radiation dosimeters in Nigeria \\ Bappah S. Yahaya ${ }^{*}$, Umar Ibrahim², Abdullahi A. Mundi ${ }^{2}$, Mustapha M. Idris ${ }^{2}$, Musa A. Bilya ${ }^{2}$, Anas Mohammed ${ }^{1}$, Musa Ali G. ${ }^{3}$

\author{
${ }^{1}$ Radiology Department, State Specialist Hospital Gombe, Gombe State, Nigeria \\ ${ }^{2}$ Department of Physics, Nasarawa State University, Keffi, Nigeria
} \\ ${ }^{3}$ Oncology Department, Federal Teaching Hospital, Gombe, Gombe State, Nigeria \\ *Corresponding author : byspindiga@gmail.com
}

Received: 20 August 2019; Accepted: 10 December 2019; Published: 16 December 2019

\begin{abstract}
Radiation dosimeters exhibit several performance properties characterized by their precision and accuracy, linearity, dose and energy dependence, stability and spatial resolution. However, these characteristics may not be satisfied by all dosimeters. The dosimetric performances of Instadose and Thermolumniscence dosimeters (TLDs) which are the two most commonly used personal dosimeters in health care institutions were comparatively assessed under clinical settings in which a GE haulum XR 6000 X-ray machine with a frequency of $50 / 60 \mathrm{~Hz}$ was used to serially irradiate Mironinstadose and TLD $100 \mathrm{H}$ badges to a controlled exposure factors and readings of absorbed doses for instadose were obtained from a portable computer with internet access, while that of TLDs was obtained through heating using Harshaw 4500 automatic TLD reader at Center for Energy Research and Training (CERT), Zaria. The dose equivalent quantities measured were; Hp (10), Hp (3) and $\mathrm{Hp}(0.07)$ all in $\mathrm{mSv}$, representing deep, eye lens and shallow doses respectively. Results of measured doses ranged between $0.74 \mathrm{mSv}$ to $22.96 \mathrm{mSv}$ for instadose and $0.71 \mathrm{mSv}$ to $35.42 \mathrm{mSv}$ for TLD badges in all performance tests conducted. Homogeneity results were $9 \%$ and $12 \%$, reproducibility was $7.2 \%$ and $3.9 \%$ while percentage deviation for linearity test was below $10 \%$ for both instadose and TL dosimeters. The performance tests results of instadose and TL dosimeters were assessed based on the criteria of the International Electrotechnical Commission (IEC) 1066 standard. The assessment revealed good performance indices within the requirement of the IEC standard. However, TL dosimeters demonstrate high sensitivity in the self-irradiation test exceeding the standard $\mathrm{mSv}$ values.
\end{abstract}

Keywords: Radiation Dosimeter, Instadose, Thermolumniscence, Absorbed dose

\section{INTRODUCTION}

X-rays were accidentally discovered in 1895 by Wilhelm Rontgen while experimenting with a Crookes tube and within five years $\mathrm{x}$-rays were utilized as diagnostic tools and even therapeutically [1]. At this time, many scientists started experimenting in the newly discovered field and it wasn't long until the biological effects of ionizing radiation were observed [2]. On Monday, August 3, 1903 a newspaper called the New York World published an article in which they described the health effects suffered by Clarence Dally, an assistant of Thomas Edison's. Mr. Dally was repeatedly exposed to an $\mathrm{x}$-ray tube during experimentation which resulted in injuries [1]. Many pioneers in the ionizing radiation field also died from diseases associated with radiation exposure [3]. It wasn't long until the researchers realized that they needed some way to measure the dose from radiation and to determine safe exposure guidelines [4]. There is the need therefore, to measure radiation level on occupationally exposed workers using dosimeters to assess the level of exposure with the aim of ensuring safe exposure levels [2,5].

Radiation dosimetry is seen as a tool used extensively for protection against ionizing radiation and could be routinely applied to occupational radiation workers, to ensure that regulatory levels were not be exceeded [6,7]. It can also be employed where ionizing radiation is unexpected, such as in the 
aftermath of the Three Mile Island, Chernobyl or Fukushima radiological hazard related incidents, such that the public irradiation is measured and calculated from a variety of indicators such as ambient measurements of radiation and radioactive contamination [8]. Other significant areas are medical dosimetry, where the required treatment absorbed dose and any collateral absorbed dose is monitored, and in environmental dosimetry, such as radon monitoring in buildings [9].

Devices, instrument or system that has the ability to measure or estimate, either directly or indirectly, the quantities exposure, kerma, absorbed dose or equivalent dose, or their time derivatives (rates), or related quantities of ionizing radiation are seen as ionizing radiation dosimeters [10]. Dosimeters coupled with their reader are referred to as a dosimetry system [7]. There are two main uses of dosimeters; for human ionizing radiation monitoring and for measurement of absorbed dose in both clinical and industrial processes. There exists a variety of electronic personal dosimeters, extremity dosimeters, and comprehensive dosimetry management systems that monitors exposure to ionizing radiation in any work environment $[11,12]$.

The instadose (Digital dosimeter) is a small, rugged dosimeter based on proprietary direct ion storage technology [13]. This breakthrough technology provides radiation workers with a precise measurement of radiation dose and includes accurate long-term exposure tracking. A built-in memory chip stores each user's identity via an embedded unique serial code that is assigned to the user [14]. Now users have the flexibility to view their radiation dose at any time from any computer with internet access. Readings via a portable computer are enabled by a universal serial bus compatible detector. Once a user receives instadose they must first register at: www.instadose.com. During the registration process the instadose driver and client are installed on the users' computer and the device is initialized for use. When a user wishes to obtain a reading they simply log-in to their account, plugin instadose to a USB port and click "Read Device". The accumulated dose stored on instadose is processed through a proprietary algorithm. This fully automated transfer of data minimizes the chance of human error and misidentification. Once complete a graphical representation of the current dose will load on the screen [15]. Some of the characteristics of instadose design that makes it an appropriate dosimeter include; USB compatible detector, Dose readings performed online by end user, Small lightweight design, Minimum Reportable Dose of $3 \mathrm{mrem}(0.03 \mathrm{mSv})$ and Lower Limit of Detection of $1 \mathrm{mrem}(0.01 \mathrm{mSv})$

Thermolumniscence dosimeter (TLD) on the other hand, incorporates anodized aluminum foil with four thermo-luminescent detectors [16]. These detectors are usually made of lithium fluoride activated with magnesium or calcium fluoride activated, in turn, with manganese [10]. The detectors store the energy received from ionizing radiation [11]. In order to know the amount of radiation received by the TL dosimeter, it is necessary to heat it to a temperature of $300^{\circ} \mathrm{C}$, thus releasing the stored energy in the form of light. The amount of light emitted is proportional to the radiation dose received by each detector [2]. The main advantages are its low cost, good tissue equivalence, easy handling, sensitivity, good precision and accuracy, it does not depend only on environmental conditions and it is reusable [17,18]. In this study, a comparison of the dosimetric performances of Instadose and TL dosimeters which are the two most commonly used personal dosimeters in health care institutions was assessed under clinical settings. Result from this study can serve as a baseline data to Radiologists, Radiographers, Oncologists, Medical physicists and other radiation health workers in judicious selection of an effective dosimeter for personal monitoring of occupational exposure to radiation during diagnosis or treatment base on the performance indices of TLD and instadose dosimeters revealed in relation to the requirement of the performance test of the IEC 1066 standard.

\section{MATERIALS AND METHODS}

\section{Materials}

The instruments that were used directly for data collection in this research study and their specification are shown in Table 3.1. 
Table 3.1: Instruments and their specification

\begin{tabular}{cll}
\hline S/No. & Instrument & Specification \\
\hline i. & X ray Machine & GE HUALUM Medical Radiography X-ray machine \\
& & $\begin{array}{l}\text { with Model number XR 6000, Serial number S0S09084 } \\
\text { and frequency of 50/60Hz manufactured October 2009: }\end{array}$
\end{tabular}

ii. Thermoluminescent Dosimeters

iii. Instadose meter

iv. Harshaw 4500 automated TLD reader

v. Portable Computer (PC) with internet access
TLD 100H: Detectors made of LiF:Mn.(Mg)/LiF:Mg, Ti (TLD-100), Reader; Harshaw 4500

Miron Inc. (GDS) Instadose dosimeters:

Badge Type;

18 - Hard Ring 31 - ID1

19 - MeasuRing ${ }^{\circledR} 37$ - ID

Hot gas type with two PMTs and nitrogen generator cooling system incorporating WinREMS software resident on a PC

SAMSUNG laptop computer with model number NPN130 and Intel Atom inside made in China.

\section{Methods}

A series of control experiments were performed by exposing the Instadose and the TLDs to a range of doses. The exposure of the dosimeters to ionizing radiation was performed with the x-ray facility in the radiology department of Federal Teaching Hospital Gombe.

The TLDs were annealed at a temperature of about $290^{\circ}$ in that releases all forms of trapped electrons prior to exposing them to a radiation source. The irradiated TLDs were read using Harshaw 4500 TLD reader. The institution where the irradiated TLDs were hired, interpreted and analyzedwas Center for Energy Research and Training (CERT) Zaria.

The instadose meters were irradiated with the same energy and exposure period. Accumulated doses from the irradiated instadosewere obtained by connecting the instadose via USB port to a PC with an internet access.

Since the main objective of this research is to evaluate and compare the performance of the dosimeters, the tests recommended in the International Electrotechnical Commission (IEC) 1066 standard were carried out and the properties that were evaluated are; homogeneity, reproducibility, linearity, fading (stability) and self-irradiation. The dosimetric performance tests were performed as follows;

\section{Homogeneity}

Eight (8) dosimeters each of TLD and Instadose were irradiated to the same level of radiation exposure factors $(120 \mathrm{kv}: 250 \mathrm{mAs})$. The measurements of the readings were used to analyze the test criteria. Variation of readings for both TLD and Instadose were evaluated using maximum and minimum values $D_{\max }$ and $D_{\min }$ as recommended by IEC (2012) such that;

$$
\frac{H_{\max }-H_{\min }}{H_{\min }} \leq 30 \%
$$




\section{Reproducibility}

Five (5) dosimeters each of the dosimeter types were irradiated using $150 \mathrm{kv}: 250 \mathrm{mAs}$ for TLD and $120 \mathrm{kv}: 250 \mathrm{mAs}$ for instadose and their readings were obtained. This procedure is repeated three times to enable the evaluation of variations of readings for each dosimeter. The mean, $\bar{x}$,standard deviation, $\sigma$, and coefficient of variations for were calculated for each dosimeter as follows;

$$
\begin{gathered}
\sigma=\sqrt{\frac{\sum_{i=1}^{n}\left(x_{i}-\bar{x}\right)^{2}}{n-1}} \\
\bar{x}=\frac{\sum_{i=1}^{n} x_{i}}{n}
\end{gathered}
$$

Where

$$
\begin{aligned}
& x_{i} \text { : Reading of } \mathrm{H}^{*}(\mathrm{~d}) \\
& \bar{x}: \text { Average reading of } \mathrm{H}^{*}(\mathrm{~d}) \\
& \quad \text { Co }- \text { efficient of variation }=\frac{\sigma_{n-1} \times 100}{\bar{x}}
\end{aligned}
$$

\section{Linearity}

Five (5) dosimeters each of the dosimeters were irradiated to different exposure factors progressively (in order of increasing dose) corresponding to the following values of doses: 0.7, 2.0, 4.2, 6.2 and 8.3 $\mathrm{mSv}$. The deviation of measured dose from the irradiated dose was calculated using the following expression,

$$
\frac{\text { Measured dose-Irradiated dose }}{\text { Irradiated dose }} \times 100
$$

\section{Fading (stability)}

Five (5) dosimeters each of TLD and instadose were irradiated at different exposure cycles at an interval of 30 days, two weeks, $48 \mathrm{hr}, 24 \mathrm{hr}$ and $0 \mathrm{hr}$ chronologically. All dosimeters were read and normalized to the dosimeters irradiated on day 0 .

\section{Self-irradiation}

Two (2) dosimeters each were stored un-irradiated for 40 days. After the storage period, they were read.

The results of these tests were evaluated according to the established performance criteria, which are based on the fulfillment of the levels of accuracy and precision required for this type of service.

\section{Methods of Data Analysis}

Data from the TLDs were generated using Harshaw 4500 Automated TLD reader at CERT, Zaria while Data from the Instadose were generated by a PC with internet access connected via USB. The results from both dosimeters were analyzed using Microsoft excel 2010 software where descriptive statistics, such as mean and standard deviation were generated and presented in tables and graphs. Standard deviation test was used to compare the mean doses calculated from the TLD read out and the doses displayed on the PC via USB from the Instadose meter. 


\section{Results and Discussion}

The data generated was analyzed based on the IEC 1066 standard on Thermoluminescence dosimetry system for personal radiation monitoring. The results were presented and discussed.

\section{Homogeneity test}

The data obtained in this performance test is presented in table 3.2 and from the result, the maximum and minimum values of dose evaluated were; $27.53 \mathrm{mSv}$ and $24.67 \mathrm{mSv}$ respectively for TLDs, whereas, that of Instadose were; $22.96 \mathrm{mSv}$ and $21.03 \mathrm{mSv}$.

Table 3.2: Performance test of TLD and Instadose response to $x$-radiation in air generated using $120 \mathrm{kv}$ and $250 \mathrm{mAs}$

\begin{tabular}{cccccc}
\hline & \multicolumn{2}{c}{ TLD readings $(\mathbf{m S v})$} & \multicolumn{3}{c}{ Instadose readings $(\mathbf{m S v})$} \\
\cline { 2 - 6 } S/No. & $\mathbf{H p}(\mathbf{1 0})$ & $\mathbf{H p}(\mathbf{0 . 0 7})$ & $\mathbf{H p}(\mathbf{1 0})$ & $\mathbf{H p}(\mathbf{3})$ & $\mathbf{H p}(\mathbf{0 . 0 7})$ \\
\hline & 24.78 & 25.30 & 22.29 & 22.29 & 22.29 \\
2 & 26.92 & 27.44 & 22.96 & 22.96 & 22.96 \\
3 & 26.16 & 26.64 & 21.90 & 21.90 & 21.90 \\
4 & 24.67 & 25.19 & 22.00 & 22.00 & 22.00 \\
5 & 27.53 & 28.01 & 22.49 & 22.49 & 22.49 \\
6 & 26.05 & 26.53 & 21.03 & 21.03 & 21.03 \\
7 & 26.88 & 27.40 & 22.24 & 22.24 & 22.24 \\
8 & 27.05 & 27.53 & 21.21 & 21.21 & 21.21 \\
\hline
\end{tabular}

The quantities of the TLD and instadose badges measured are personal dose equivalent $\operatorname{Hp}(10)$ for deep dose, $\mathrm{Hp}(3)$ for eye lens and $\mathrm{Hp}(0.07)$ for shallow dose.

Substituting the evaluated values in expression (2.1), a factor of 0.12 was obtainedfor TLD and 0.09 for Instadose representing $12 \%$ and $9 \%$ of percentage variation of readings. In general, the mean values of the evaluated doses for both dosimeters and their standard deviation were; $26.26 \pm 0.02 \mathrm{mSv}$ for TLD and $22.02 \pm 0.02 \mathrm{mSv}$ for Instadose. Based on the results, both dosimeters demonstrate precision in homogeneity and have satisfied the criterion as described by the IEC 1066 . This finding is in line with the findings of $[13,19,20]$. However, this result is not in line with [21] who found the difference between the maximum and minimum evaluated values of a DIS dosimeter to be greater than $30 \%$. This may be due to the difference in the method of irradiation adopted in the research procedure.

\section{Reproducibility test}

Individual sensitivity responses were obtained in the range of $32.50 \mathrm{mSv}$ to $35.42 \mathrm{mSv}$ for TLDs and $20.96 \mathrm{mSv}$ to $22.96 \mathrm{mSv}$ for instadose. The standard deviation, $\sigma$, was calculated using expression (2.2) and found to be approximately $1 \%$ for each dosimeter. The mean values of the overall irradiations were $34.15 \mathrm{mSv}$ for TLD and $22.14 \mathrm{mSv}$ for instadose which was obtained using expression (2.3) as shown in table 3.3. 
Table 3.3: Sensitivity response variation of Instadose and TLDs to three given irradiations and readings for $\mathrm{Hp}(10)$

\begin{tabular}{ccccccc}
\hline \multirow{2}{*}{ S/No. } & \multicolumn{7}{c}{ Readings obtained according to irradiation (mSv) } \\
\cline { 2 - 7 } & \multicolumn{2}{c}{$\mathbf{1}^{\text {st }}$ Irradiation } & \multicolumn{2}{c}{$\mathbf{2}^{\text {nd }}$ Irradiation } & \multicolumn{2}{c}{$\mathbf{3}^{\text {rd }}$ Irradiation } \\
\hline & Instadose & TLD & Instadose & TLD & Instadose & TLD \\
\hline 1 & 22.96 & 33.71 & 21.90 & 34.95 & 22.24 & 35.43 \\
2 & 21.90 & 33.61 & 22.24 & 33.82 & 20.96 & 35.42 \\
3 & 22.24 & 33.21 & 22.29 & 33.72 & 22.49 & 33.71 \\
4 & 22.29 & 34.78 & 22.49 & 33.33 & 21.90 & 33.82 \\
5 & 22.49 & 32.50 & 21.90 & 35.25 & 22.03 & 35.04 \\
\hline
\end{tabular}

Generally, in the reproducibility performance test, the determined coefficient of variation obtained for instadose badges from expression (3.4) has an average value of $3.3 \%$ for the dosimeters separately and $7.2 \%$ collectively. While, the evaluated coefficient of variation for TLD badges have an average values of $2.1 \%$ separately and $3.9 \%$ collectively. The average percentage deviations analyzed using expression (3.1) for the TLD and instadose dosimeter badges were found to be $4.8 \%$ and $2.8 \%$ respectively. These findings are in tandem with the findings of $[22,13,23,19,24,20]$.

\section{Linearity test}

The linearity of responses from both dosimeters for dose range of $0.7 \mathrm{mSvto} 8.3 \mathrm{mSv}$ is shown in Table 3.4.

Table 3.4: The results of linearity of responses from TLD and Instadose for dose range of $0.7 \mathrm{mSv}$ to $8.3 \mathrm{mSv}$ in air.

\begin{tabular}{ccc}
\hline $\begin{array}{c}\text { Irradiated dose } \\
(\mathbf{m S v})\end{array}$ & $\begin{array}{c}\text { Measured dose }(\mathbf{m S v}) \\
\text { for TLD }\end{array}$ & $\begin{array}{c}\text { Measured dose (mSv) for } \\
\text { Instadose }\end{array}$ \\
\hline 0.7 & 0.71 & 0.74 \\
2.0 & 2.32 & 2.50 \\
4.2 & 4.45 & 4.66 \\
6.2 & 6.30 & 6.50 \\
8.3 & 8.50 & 8.70 \\
\hline
\end{tabular}

The average measured readings of the irradiations were plotted against the irradiated dose as shown in Figure 3.1. A linear correlation between delivered and measured dose has been established by plotting a graph. Also, the percentage deviation of measured dose from the irradiated dose was calculated using expression (2.5) and was found to be between $1.43 \%$ to $6.0 \%$ and $3.8 \%$ to $6.5 \%$ for TLD and instadose dosimeters respectively. These values lie far below 10\% indicating that the IEC 1066 standard requirement has been met by both dosimeters. The findings tallies with the findings of $[13,21,20,23,24]$. 


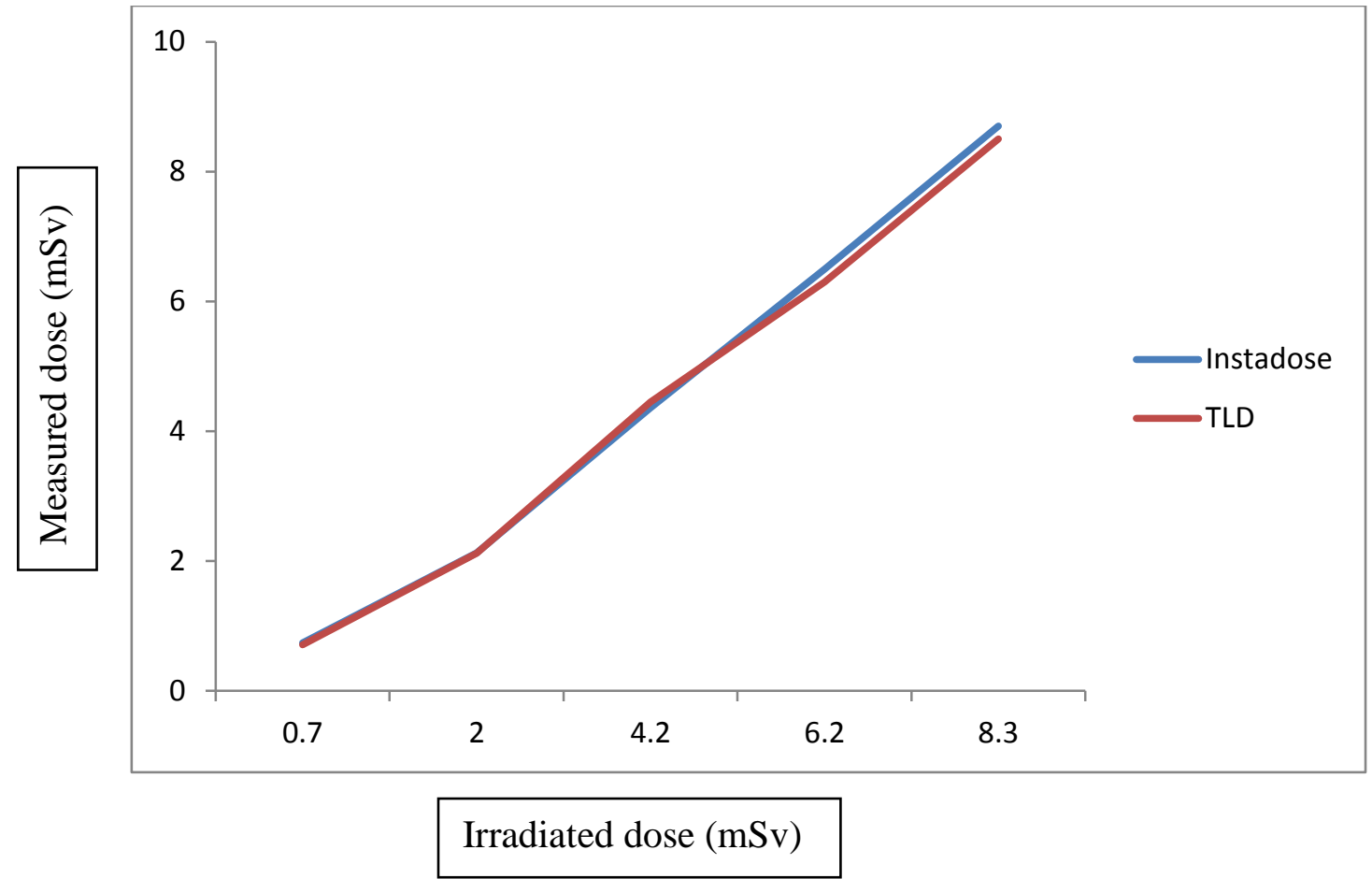

Figure 3.1: Linearity of TLD and Instadose dosimeters for Hp (10)

\section{Fading (stability) check}

The data of the test corrected for background and expressed in percentages of dose received is shown in Table 3.4.The objective of this test was to evaluate the stability of the TL and Instadose dosimeters over a month exposure period under environmental condition.Based on the data, the dose indicates 98.3\% for $\mathrm{Hp} \mathrm{(10)} \mathrm{and} 98.0 \%$ for $\mathrm{Hp}(0.07)$ after storage period of 30 days for TLDs, whereas, both dose equivalent quantities read $100 \%$ for instadose check.

Table 3.5: Fading check of Instadose and TLD response for 30 days storage period at $25{ }^{0} \mathrm{C}$ temperature

\begin{tabular}{cccccc}
\hline $\begin{array}{c}\text { Storage } \\
\text { Period } \\
\text { (days) }\end{array}$ & \multicolumn{2}{c}{ TLDs Mean Reading (\%) } & \multicolumn{3}{c}{ Instadose Mean Reading (\%) } \\
\cline { 2 - 6 } & Hp (10) & Hp (0.07) & Hp (10) & Hp (3) & Hp (0.07) \\
\hline 0 & 100 & 100 & 100 & 100 & 100 \\
1 & 99.1 & 99.1 & 100 & 100 & 100 \\
2 & 99.0 & 98.9 & 100 & 100 & 100 \\
15 & 99.0 & 98.9 & 100 & 100 & 100 \\
30 & 98.3 & 98.0 & 100 & 100 & 100 \\
\hline
\end{tabular}

The results of the fading (stability) check, has revealed that there was no any significant fading over the exposure period. The evaluated loss of signal value was found to be less than $2 \%$. Thus, the IEC 1066 requirement, which is $10 \%$ for 90 days under standard test conditions, is met. The finding of this test is in agreement with the findings of $[25,20,21]$.

\section{Self-irradiation test}

The analyzed data obtained from Table 3.5 showed that the TLDs received radiation of $0.11 \mathrm{mSv}$ and $0.09 \mathrm{mSv}$, while the results of the instadose after the prescribed storage period were $0.00 \mathrm{mSv}$. 
Table 3.6: Data of zero point readings after 40 days storage without irradiation

\begin{tabular}{cc}
\hline TLD readings $(\mathbf{m S v})$ & Instadose readings $(\mathbf{m S v})$ \\
\hline 0.11 & 0.00 \\
0.09 & 0.00 \\
\hline
\end{tabular}

The result of this test demonstrates zero self-irradiation readings for instadose, whereas, slight increase in sensitivity and self-irradiation value $(0.01 \mathrm{mSv})$ is recorded in one of the TLD badges exceeding the requirement of the IEC 1066 standard, whereas, instadose indicates $0.00 \mathrm{mSv}$ after storage period of about 30 days meeting the standard requirement.The findings of the instadose point readings tallies with $[25,21$,$] . However, the findings of the TLD point readings does not agree with$ the findings of $[25,21]$ where they obtained $0.08 \mathrm{mSv}$ after storage period of 91 days. This can be due to accumulation of extraneous variables due to temperature variations in the course of transporting TL dosimeters from the research site to the TL reading center which covers about $600 \mathrm{Km}$.

In general, the results of all the tests were obtained through evaluation with the confidence interval according to the IEC 1066 standard as described in Table 3.7, which summarized and compared the results of this study with the IEC 1066 standard.

Table 3.7: Summary and comparison of results of TLD and Instadose dosimeters characteristics performance evaluation

\begin{tabular}{|c|c|c|c|c|}
\hline & Evaluation & $\begin{array}{c}\text { IEC } 1066 \\
\text { Performance criteria for TLD }\end{array}$ & $\begin{array}{c}\text { Results } \\
\text { obtained for } \\
\text { TLD } \\
\end{array}$ & $\begin{array}{l}\text { Results obtained } \\
\text { for Instadose }\end{array}$ \\
\hline i. & $\begin{array}{l}\text { Badge } \\
\text { Homogeneity }\end{array}$ & $\begin{array}{l}\text { The difference between the } \\
\text { maximum and minimum } \\
\text { evaluated values should not } \\
\text { exceed } 30 \%\end{array}$ & $12 \%$ & $9 \%$ \\
\hline ii. & $\begin{array}{l}\text { Reproducibility of } \\
\text { Badges }\end{array}$ & $\begin{array}{l}\text { The co-efficient of variation } \\
\text { should not exceed } 7.5 \% \text { for } \\
\text { each dosimeter separately and } \\
\text { all dosimeters collectively }\end{array}$ & $\begin{array}{c}2.1 \% \text { separately } \\
3.9 \% \\
\text { collectively }\end{array}$ & $\begin{array}{l}3.3 \% \text { separately } \\
7.2 \% \text { collectively }\end{array}$ \\
\hline iii. & Linearity & $\begin{array}{c}\text { The dosimeters response } \\
\text { variation should not be more } \\
\text { than } 10 \% \text { over the range of } 0.1 \\
\mathrm{mSv} \text { to } 1 \mathrm{~Sv}\end{array}$ & $6.0 \%$ & $6.5 \%$ \\
\hline iv. & Stability & $\begin{array}{l}\text { Evaluated values of dosimeters } \\
\text { shall not differ from the } \\
\text { conventional values by more } \\
\text { than } 10 \% \text { for } 90 \text { days at } 20^{\circ}\end{array}$ & $2.0 \%$ & $0.0 \%$ \\
\hline v. & Self-Irradiation & $\begin{array}{l}\text { After storage period of } 30 \text { days, } \\
\text { the zero point shall not exceed } \\
\qquad 0.1 \mathrm{mSv}\end{array}$ & $0.11 \mathrm{mSv}$ & $0.0 \mathrm{~Sv}$ \\
\hline
\end{tabular}




\section{CONCLUSION}

The performance of TLD and Instadose dosimeter systems has been studied under clinical conditions. Both dosimeters were evaluated based on the criteria of IEC 1066 standard for personal monitoring. The results of the tests carried out on homogeneity, reproducibility, linearity, stability and selfirradiation has shown that, both dosimeters demonstrate good performance and has pass the entire tests requirement carried out except for TLD which demonstrate slight increase in $\mathrm{mSv}$ values $(0.01)$ in the self-irradiation test. Based on the result of this study, Instadose dosimeter is recommended for routine personal $\mathrm{x}$-radiation monitoring.

\section{Acknowledgement}

The authors wish to acknowledge the support of the Radiology department, Federal Teaching Hospital Gombe, Nigeria and Center for EnergyResearch and Training, (CERT) Zaria, Nigeria who consented to the use of their facilities forTLDs irradiation and reading respectively.

\section{REFERENCES}

[1] Steven, J. C. (2016). The suitability of active personal dosimeters as the legal dosimeter for PET Radioisotope workers.An M.Sc. Dissertation submitted to school of postgraduate studies, The University of Western Australia (Unpublished) 13-19

[2] Bappah S. Yahaya, Umar Ibrahim, Samson D. Yusuf, Abdullahi A. Mundi , Mustapha M. Idris, Habib Sa'ad, Anas Mohammed \& Reuben J. Soja (2019). Performance Evaluation of Thermolumniscence Dosimeters in Personnel in-Vivo Dosimetry, DUJOPAS, 5 (2): 195-203

[3] United Nations Scientific Committee on the Effects of Atomic Radiation (UNSCEAR) (2006).Effects of Ionizing Radiation.United Nations, New York (1)

[4] Boyd, W. L. (2009). Using Thermoluminescence Dosimeters to Measure the Dose From High and Low Energy X-Ray Sources. Message posted to UNLV Theses, Dissertations, Professional Papers, and Capstones. Accessed on $11^{\text {th }}$ November, 2018 from http://digitalscholarship.unlv.edu/thesesdissertations/1203

[5] International Atomic Energy Agency (IAEA) (2002). Occupational radiation protection: Protecting workers against exposure to ionizing radiation.Proceedings of an International Conference, Geneva, 26-30 August 2002

[6] International Commission on Radiological Protection (ICRP) (1990).Report 60 Recommendations of the International Commission on Radiological Protection. Publ 60, Ann ICRP 21 (1-3)

[7] Aya, M. H. A. (2018). New Trend in Radiation Dosimeters.American Journal of Modern Physics, 7(1), 21-30. https://doi.org/10.11648/j.ajmp.20180701.13

[8] Antonio, P., Pinto, T. N. O. \& Caldas, L. V. E. (2010).TL and OSL techniques for calibration of ${ }^{90} \mathrm{Sr}+{ }^{90} \mathrm{Y}$ clinical applicators.Dosimetry Poster presentations, Helsinki, Finland, 4(03), 769-775

[9] Izewska, J. \&Rajan, G. (2012).Radiation dosimeters. Dosimetry and Medical Radiation Physics. Message posted to IAEA. Accessed on $11^{\text {th }}$ November, 2018 from: http://www.naweb.iaea.org/nahu/dmrp/pdf files/Chapter3

[10] Singh, V.P., Managanvi, S.S., Bihari, R.R. \&Bhat, H.R. (2013). Operational experience of electronic active personal dosimeter and comparison with CaSo4:Dy TL dosimeter in Indian PHWR. Radiation Protection Dosimetry, 156(1), 93-102.

[11] Seco, J., Clasie, B. \& Partridge, M. (2014). Review on the characteristics of radiation detectors for dosimetry and imaging. Phys. Med. Biol., 59 (20), 303-347. https://doi:10.1088/0031-9155/59/20/R303

[12] Lummis, S. (2013). Personal Radiation Monitoring System Inefficiencies: A Comparison in Service Provision. In Proceedings of the 2013 Conference of the ACPSEM, Pan Pacific Hotel Perth, 2013, 226

[13] Garzón, W. J., Khoury, H., Ovalle, S. A. M. \& Medeiros, R. B. (2018).Performance of the Instadose dosimeter for interventional radiology and cardiology application.Radiation Protection Dosimetry, 1(7), 2, https://doi.org/10.1093/rpd/ncy172

[14] Miron (2018).Instadose Dosimeter, Instant, Precise, Portable. Accessed on $8^{\text {th }}$ October, 2018 from http://www.miron.com 
[15] Ginjaume, M. (2011).Performance and approval procedures for active personal Dosimeters.Radiation Protection Dosimetry, 144 (1-4), 144-149, https://doi.org/10.1093/rpd/ncq457

[16] Covens, P., Berus, D., Buls N., Clerinx, P. \&Vanhavere, F. (2007).Personal dose monitoring in hospitals: Global assessment, critical applications and future needs.Radiation Prot. Dosimetry, 124(3), 250-259

[17] Furetta, C. \&Weng, P.S. (1997).Operational Thermoluminescence Dosimetry.World Scientific, Singapore, 3(1-2), 22-28

[18] Koguchi, Y., Yamamoto, T. \& Maria R. (2010). Intercomparison of various dosimetry systems for routine individual monitoring.Dosimetry Oral presentations, Helsinki, Finland,4(19) 835

[19] Sabine, M., Markus, B. \& Annette, F. S. (2010). Reproducibility assessment fora new neutron dose evaluation system.Dosimetry Poster presentations, Helsinki, Finland, 4(01), 755-758

[20] Daniel, M., Ailza, C. S., Elizaima, F. S. \& Ernesto, M. H. (2000). Characteristics of a Thermoluminescence Dosimetry System based on LiF:Mg,Cu,P (GR-200) Detectors for Environmental Monitoring. Rad. Prot. Dosimetry, 60(2), 147-153

[21] Nguyen, P. D.,Takashi, M., Katsuhiro, O., Kazuichi, O. \& Hiroyuki, M. (2001). Basic characteristics examination of Direct Ion Storage (DIS) dosimeter.Japan Atomic Energy Research Institute, JP0150733 047

[22] Pugliese, M., Roca, V. \& Durante, M. (2010).The use of TL dosimeters in HZE radiation fields.Dosimetry Poster presentations, Helsinki, Finland, 4(19), 832-834

[23] Campos, L. L., Rocha, F. D., \& Campos, V. (2010). CaSO4:Dy TL response for photons energies between $33 \mathrm{keV}$ to $15 \mathrm{MeV}$. Dosimetry Poster presentations, Helsinki, Finland, 4(09), 797-798.

[24] Teixeira, M. \& Caldas, L V. E. (2010).Dosimetric properties of agate stones.Dosimetry Poster presentations, Helsinki, Finland, 4(14), 811-816.

[25] Andrew, V. \& Braden, G. (2019).Loss of TLD signal due to high temperature environmental conditions. Radiation Protection Dosimetry, 130 (34), 1-4, https://doi.org/10.1093/rpd/ncz130 